\title{
Notas sobre os conceitos de comunidade, \\ comunicação comunitária e dialogia
}

Marcelo Ernandez Macedo

Doutor em Ciências Sociais (PPCIS-Uerj) e Professor Adjunto da Faculdade de Comunicação Social da Uerj.

E-mail: marcelo.ernandez@gmail.com

Livia Maria Abdalla Gonçalves

Mestre em Comunicação, Desenvolvimento e Mudança Social (Complutense/Madrid). Bolsista de apoio a pesquisa, ensino e extensão (Proatec) da Uerj.

E-mail: livia.abdalla@gmail.com

Resumo: A proposta deste artigo é discutir o conceito de comunicação comunitária. Para tal, parte-se de uma breve revisão e de algumas aplicações do conceito de comunidade, em diferenciação à concepção de sociedade. Diante do desenvolvimento das tecnologias da comunicação, abordam-se as diferentes formas de manifestação social do ideário ligado à comunidade, demonstrando-se como o conceito é central para a compreensão dos processos de comunicação desenvolvidos hoje. Ao final deste percurso, será analisado como o conceito de dialogia, inaugurado por Bakhtin e desenvolvido por Freire, relaciona-se à comunicação comunitária e significa novas perspectivas para a Teoria da Comunicação e, em última instância, para a própria Teoria Política.

Palavras-chave: comunidade; sociedade; comunicação comunitária; comunicação dialógica; democratização da informação.
Abstract: The aim of this paper is to debate on the concept of community communication. To this end, we conduct a brief review of some usages of the concept of community, in distinction to the conception of society. In face of the development of the communication technologies, we address the different forms of social manifestation of the perspectives related to the community, showing that this is a focal concept to the comprehension of the communication processes developed nowadays. In the end of the discussion, we analyse how the concept of dialogue, created by Bakhtin and developed by Freire, is related to the community communication and how it matters to the news perspectives of Communication and, ultimately, to the Political Theory itself.

Keywords: community; society; community communication; dialogical communication; democratization of information.

\section{INTRODUÇÃO}

Este estudo tem como principal referência o trabalho realizado na Faculdade de Comunicação Social da Uerj, por meio da participação em um grupo de estudos 
e extensão sobre comunicação comunitária. Além de discutir a bibliografia relacionada ao tema, entramos em contato com diversos grupos da região metropolitana do Rio de Janeiro que promovem esse tipo de comunicação, seja exercendo-a efetivamente, seja formando pessoas para tal. O trabalho vale-se também da experiência de mais de dez anos de pesquisas antropológicas de um dos autores junto a movimentos sociais rurais.

No início de 2012, iniciamos um trabalho mais sistemático de acompanhamento de alguns grupos com os quais entramos em contato ao longo de 2011. Temos como objetivos produzir conhecimentos sobre a comunicação comunitária, desenvolver projetos de extensão baseados na troca de conhecimentos e contribuir para a integração entre os grupos de comunicação comunitária do estado do Rio de Janeiro. Por meio do método da pesquisa de campo com observação participante, sistematizamos as informações colhidas e auxiliamos os grupos com os quais estamos mantendo contato. Procurando unir ensino, pesquisa e extensão, trabalhamos no sentido de fortalecer os grupos de comunicação comunitária, proporcionar aos alunos da faculdade o aprendizado proveniente dessa participação e gerar conhecimento sobre o tema.

O principal objetivo deste texto é discutir o conceito de comunicação comunitária e algumas questões relacionadas a este campo. Nosso ponto de partida será o debate sobre o conceito de comunidade.

\section{COMUNIDADES - DAS PRIMEIRAS ÀS NOVAS LEITURAS DO CONCEITO}

Uma das principais referências para tal são as compilações de Florestan Fernandes, que tratam da definição, diferenciação e aplicação dos conceitos de comunidade e sociedade. Em um primeiro volume ${ }^{1}$, o autor reúne a contribuição teórica dos diversos autores brasileiros e estrangeiros que tratam da diferenciação entre os dois conceitos. Em outro volume ${ }^{2}$, Fernandes reúne breves etnografias de grupos comunitários e societários brasileiros que utilizam como base teórica os autores clássicos estudados no primeiro.

Por meio dos autores reunidos por Fernandes, percebe-se que a ideia de comunidade remete ao sentimento de vida em comum fundado nas relações de

1. FERNANDES, Flores$\tan$ (org.). Comunidade e sociedade: leituras sobre problemas conceituais, metodológicos e de aplicação. São Paulo: Nacional, 1973.

2. FERNANDES, Florestan (org.). Comunidade e sociedade no Brasil. São Paulo: Nacional, 1975.

3. WEBER, Max. Economia e sociedade. Brasília: Editora UNB, 1991. parentesco e vizinhança, baseado na reciprocidade, norteado por laços afetivos que ligam indivíduos que convivem em um mesmo espaço físico e nele adquirem os recursos básicos para a sua subsistência. Cada um dos autores apresentados por Fernandes atribui valor a um ou outro dos atributos. Mas, se pudéssemos identificar um tipo ideal de comunidade, no sentido weberiano do termo ${ }^{3}$, a partir dos diversos autores reunidos por Fernandes, esta teria: base territorial comum, fortes laços afetivos, reciprocidade, autonomia política e econômica e subordinação do individual ao social.

Já uma sociedade seria definida por relações voluntárias e contratuais. $\mathrm{Na}$ medida em que compartilham determinado interesse, indivíduos podem 
se associar para alcançar objetivos relacionados ao mesmo, embora não necessariamente tenham outros aspectos de suas vidas compartilhados, tais como relações de parentesco, interdependências econômicas ou convivam numa mesma base territorial. Portanto, o conceito de sociedade é mais amplo e inclui o de comunidade.

Essa diferenciação conceitual vem à tona a partir do aprofundamento do processo da divisão social do trabalho. A fragmentação das atividades laborais, a prevalência do contrato sobre o status, a multiplicação dos grupos formais, a passagem da família para o Estado como forma de organização social predominante e a ampliação e internacionalização das trocas comerciais são algumas condições sociais que promovem modos de vida societários e fundamentam a separação conceitual entre comunidade e sociedade ${ }^{4}$; e, mesmo, sugerem a passagem da primeira forma à segunda como modo predominante de agrupamento social, embora a bibliografia seja quase unânime em afirmar a coexistência entre as duas formas sociais ao longo da História.

Alguns autores promovem esforços no sentido de superar a dicotomia comunidade e sociedade. Para Paiva, por exemplo, comunidade e sociedade não podem ser vistas como diferenças absolutas, mas, sim, como modos de relacionamento humano complementares.

Comunidade é a metáfora que, aqui, nos parece adequada para a construção de uma nova forma para o laço social. Não a usamos no quadro da bipolaridade substancial com que frequentemente se interpreta, na vulgarização sociológica, a famosa dicotomia de Tönnies, e sim como um caminho de rediscrição das tentativas sociais de produzir comunicação a partir de uma experiência comum. Comunidade é, então, o que permite aos indivíduos e aos grupos vislumbrar a abertura para estender criativamente novas pontes sobre a dissociação humana ${ }^{5}$.

A partir das sugestões da autora, estamos diante de um processo de criação de novos sentidos e formas de experiência comum que tendem a transformar a concepção clássica de comunidade. Na busca, na medida em que as novas tecnologias da informação permitem a criação de laços sociais independentemente da presença física, vem imediatamente à tona o debate sobre a relevância do território como base para a experiência comum.

Um dos autores mais citados quando falamos dessa questão é Pierre Lévy. Vejamos o que diz o autor sobre a construção de laços sociais a partir da cibercultura e da popularização do universo das chamadas "comunidades virtuais":

A cibercultura é a aspiração da expressão de construção de um laço social, que não seria fundado nem sobre links territoriais, nem sobre relações institucionais, nem sobre as relações de poder, mas sobre a reunião em torno de centros de interesses comuns, sobre o jogo, sobre o compartilhamento do saber, sobre a aprendizagem cooperativa, sobre processos abertos de colaboração. O apetite para as comunidades virtuais encontra um ideal de relação humana desterritorializada, transversal, livre. As comunidades virtuais são os motores, os atores, a vida diversa e surpreendente do universal por contato ${ }^{6}$.
4. WIRTH, L. Delineamentos e problemas da comunidade. In: FERNANDES, F. (org.). Comunidade e sociedade: leituras sobre problemas conceituais, metodológicos e de aplicação. São Paulo: Nacional/Edusp, 1973, p. 86.

5. PAIVA, RAQUEL. O espírito comum - Comunidade, mídia e globalismo. Rio de Janeiro: Mauad, 2003, pp. 10-11.

6. LÉVY, Pierre. Cibercultura. Rio de Janeiro: Editora 34, 1999, pp. 132-133. 
7. COSTA, R. Por um novo conceito de comunidade: redes sociais, comunidades pessoais e inteligência coletiva. Interface-Comunicação, Saúde e Educação. São Paulo, Unesp, v. 9, n.17, mar./ago. 2005, p. 247.

8. BOURDIEU, Pierre. O poder simbólico. Rio de Janeiro: Bertrand Brasil, 1989

9. DELEUZE, Gilles; GUATTARI, Félix. Mil platôs - Capitalismo e esquizofrenia. Coleção Trans. Rio de Janeiro: Editora 34, 1995.
Podemos perceber que a caracterização da formação de laços sociais por meio das comunidades virtuais desse autor não leva em consideração a diferenciação entre os conceitos de comunidade e sociedade. Sem fazer qualquer referência explícita aos conceitos de comunidade e sociedade, ele mistura atributos dos dois tipos de formação social. Ao mesmo tempo em que fala sobre esses novos tipos de comunidade, baseadas na desterritorialização, as fundamenta a partir da comunhão de interesses comuns, mais relacionados à ideia de sociedade, porém com atributos do clássico conceito de comunidade, tais como a colaboração para a reprodução social.

Caso viéssemos a pensar o universo da cibercultura a partir da diferenciação entre comunidade e sociedade, tenderíamos a escolher outro termo para o que se costuma chamar de "comunidade virtual", pois entendemos que faltaria não só o atributo território, mas outros fundamentais, como o sentimento de vida em comum, interdependência econômica e a formação de fortes laços afetivos (embora até possam vir a se formar). Acreditamos que o universo da cibercultura lida, sobretudo, com grupos de interesse, com pessoas que se associam para tratar de questões específicas em comum e, nesse sentido, seria mais correto chamá-los de "sociedades virtuais". Mas, nesse debate, há aqueles que vão mais longe, propondo a falência do conceito de comunidade e sua substituição por outros.

Costa, por exemplo, propõe a "transmutação" do conceito de comunidade para o de redes sociais. Segundo o autor:

Não se trata mais de definir relações de comunidade exclusivamente em termos de laços próximos e persistentes, mas de ampliar os horizontes na direção das redes pessoais. É cada indivíduo que está apto a construir sua própria rede de relações, sem que essa rede possa ser definida precisamente como comunidade ${ }^{7}$.

O autor acredita que, atualmente, os laços sociais sejam muito mais uma questão de escolha individual. Associando-se a Bourdieu e seu conceito de capital social ${ }^{8}$, sugere que tudo depende da capacidade de interação entre os indivíduos, do seu potencial para interagir com os que estão à sua volta, e também com os que estão distantes e podem ser acessados remotamente. Nesse sentido, as novas tecnologias da informação seriam grandes instrumentos para o desenvolvimento de capital social. Tudo dependeria da capacidade individual de ser simpático e criar relações de confiança nessas novas redes.

Embora o caminho traçado por Costa tenha passagens que podem contribuir para o debate, introduzindo conceitos e autores relevantes, tais como o de rizoma, de Deleuze e Guattari ${ }^{9}$, suas pontes estão calcadas em estruturas que me parecem sociologicamente frágeis. $\mathrm{O}$ autor trata a formação de laços sociais como uma questão de capacidade, o que significa uma redução significativa do conceito de Bourdieu de capital social, que, segundo ele, não depende somente das estratégias individuais desenvolvidas dentro de cada grupo social, mas também dos constrangimentos impostos por cada membro dos grupos para a entrada e participação, o que poderíamos chamar de sua dimensão 
institucional. Em outras palavras, o capital social se forma a partir de relações de poder desenvolvidas dentro de cada campo social e, nessa perspectiva relacional de poder, não importa somente a capacidade de acumular recursos, mas também o valor que os agentes sociais lhes atribuem. A versão liberal do conceito de capital social de Costa despreza o fato de que os agentes sociais, embora aptos a fazer escolhas e superar constrangimentos, estão condicionados por suas próprias trajetórias pessoais e coletivas, que definem posições de classe, gênero, geração etc.

Outra fragilidade do texto de Costa aparece quando o autor fala sobre simpatia e confiança como bases para a formação de capital social. Sennett ${ }^{10}$ nos mostra que a confiança é criada a partir da repetição de padrões de relacionamento; que esta se fortalece quando, numa relação, determinado ator pode esperar determinado comportamento de seu par. Nesse sentido, a rotina exerceria importante papel, pois está relacionada à repetição de padrões de comportamento. $\mathrm{O}$ autor despreza o fato de que a confiança prescinde de laços fortes e persistentes e que o caráter efêmero das relações sociais na atualidade ao mesmo tempo reflete e é reflexo das dificuldades para o estabelecimento de relações de confiança entre as pessoas.

Portanto, a simples "transmutação" do conceito de comunidade para o de redes sociais nos parece apressada. Trata-se de conceitos distintos com aplicações distintas, não havendo como simplesmente substituir um pelo outro. Paiva consegue perceber as contradições envolvidas na discussão sobre a base territorial referente ao conceito de comunidade e as transformações inerentes às novas tecnologias da informação. Segundo a autora, se, por um lado, precisamos redefinir a influência da territorialidade na análise do conceito de comunidade, por outro, não se pode desprezar o fato de os homens terem relações marcantes com o espaço físico em que vivem.

De fato, o homem, como tantos outros animais, desenvolve "instintos territoriais", e carrega de afetividade o espaço que ocupa e se identifica com ele. Se os sistemas tecnológicos de informação não puderem reproduzir a riqueza das comunicações pessoais, as relações pessoais serão sempre humanamente mais ricas do que aquelas mediadas pela tecnologia ${ }^{11}$.

Nesse ponto, Lévy parece restabelecer a diferenciação entre as ideias de comunidade e sociedade, pois sugere que a interatividade possibilitada pelas novas tecnologias da informação pode servir para recriar a sociabilidade urbana, em vez de substituir a diversidade, o contato físico e os encontros humanos:

Nem analogia (entre ciberespaço e cidade), nem assimilação, a perspectiva que proponho consiste em pensar a articulação destes dois espaços qualitativamente diferentes, o do território e o da inteligência coletiva ${ }^{12}$.

Estivemos tentando analisar a aplicação do conceito de comunidade ao universo urbano em geral. Mas, ao analisarmos as etnografias reunidas por Fernandes para aplicar o conceito de comunidade, percebemos que todas se referem a grupos que vivem em meios rurais. Tanto os caipiras paulistas ${ }^{13}$, como
10. SENNETT, Richard. A corrosão do caráter Consequências pessoais do trabalho no novo capitalismo. Rio de Janeiro: Record, 1999.

11. PAIVA, op. cit., p. 76.

12. LÉVY, op. cit., p. 199. 13. CANDIDO, Antonio. 1975. O caipira e sua cultura. In: FERNANDES, Florestan (org.). Comunidade e sociedade no Brasil. São Paulo: Nacional, 1975, pp. 51-59. 
14. QUEIROZ, Maria Isaura Pereira. 1975. O povoado de Santa Brígida. In: FERNANDES, Florestan (org.). Comunidade e sociedade no Brasil. São Paulo: Nacional, 1975, pp.60-66.

15. WAGLEY, C.; GALVÃO, E. 1975. Caboclização das comunidades Tenetehara. In: FERNANDES, Flores$\tan$ (org.). Comunidade e sociedade no Brasil. São Paulo: Nacional, 1975, pp. 21-34.

16. MARX, Karl. O capital - Crítica da economia política. 19. ed. Rio de Janeiro: Civilização Brasileira, 2002.

17. BAUMAN, Zygmunt. Comunidade - A busca por segurança no mundo atual. Rio de Janeiro: Jorge Zahar, 2003. os baianos e alagoanos de Santa Brígida ${ }^{14}$, e também os índios tenetehara ${ }^{15}$, são grupos que têm na agricultura sua principal fonte de subsistência. $\mathrm{O}$ senso de vida em comum a partir da afetividade das relações de parentesco, vizinhança e compadrio, o pertencimento a um mesmo território e a prevalência das relações de reciprocidade são características das comunidades rurais. Portanto, é nos meios rurais onde verificamos com mais facilidade a presença dos atributos que qualificam um grupo social como comunitário, de acordo com as principais referências bibliográficas sobre o tema.

Embora mais adequado aos grupos rurais, o conceito vem sendo largamente aplicado como uma forma politicamente correta de designar os grupos que vivem nas favelas dos grandes centros urbanos, independentemente da presença dos atributos que identificamos para o conceito. No Rio de Janeiro, especialmente, comunidade é sinônimo de favela. Mas seria possível comparar os grupos sociais que vivem em favelas com os grupos que vivem no campo? Aqueles que não conhecem a nossa história poderiam dizer que não, pois se trata de contextos totalmente distintos e, portanto, os modos de vida seriam também bastante diferentes, não sendo possível relacionar. Contudo, não é necessário conhecer profundamente a nossa história recente para saber que a maior parte das pessoas com mais de 40 anos que vive nas favelas dos grandes centros urbanos tem origem rural. Nossas favelas foram formadas principalmente a partir do êxodo rural que inverteu a situação habitacional no Brasil ao longo do último século. Se, em 1920, tínhamos $80 \%$ da população morando no campo e apenas $20 \%$ nas cidades, em 1980 as porcentagens estavam invertidas. Nosso processo de industrialização, alavancado a partir de 1930, é resultado do processo de expropriação dos meios de produção sofrido por grandes contingentes de trabalhadores rurais que se instalaram em favelas dos grandes centros e que passaram a constituir os "exércitos de reserva" para a indústria e o comércio ${ }^{16}$.

Portanto, parte significativa dos favelados tem origem nos meios rurais, conhece seus modos de vida e podemos dizer que, mesmo passado o tempo e alterado drasticamente o contexto, carrega ainda alguns atributos e alguma coisa do ethos característico dos meios rurais. Assim, sem querer, sem saber, o senso comum acaba acertando em parte quando chama uma favela de comunidade. Em certo sentido, se há locais nos grandes centros que se aproximam do ethos comunitário, a maior parte desses locais são favelas. De certo modo, o termo está na moda, como afirma Bauman ${ }^{17}$, pois parece oferecer a sensação de proximidade social, afetividade e segurança que tanto necessitamos em um mundo marcado pela imprevisibilidade, pelo caos. E, não é uma coincidência que favelados, caipiras e indígenas sejam hoje as populações mais discriminadas em nosso país, vítimas de estereótipos diariamente reforçados pelos meios de comunicação de massa.

Nesse ponto, voltemos à nossa questão inicial. Já vimos como o conceito de comunidade é central para a compreensão das dinâmicas sociais tanto nos meios rurais como nos urbanos. Permanece ainda a questão: o que seria comunicação comunitária? Como o conceito se insere no âmbito das Teorias da 
Comunicação? E como a sua aplicação pode contribuir para democratizar as sociedades capitalistas?

\section{COMUNIDADE E COMUNICAÇÃO}

Segundo Dewey, há mais do que um laço verbal entre as palavras comum, comunidade e comunicação: "Os homens vivem em comunidade em virtude das coisas que têm em comum; e comunicação é a maneira pela qual passam a possuí-las em comum"18. A partir daí, poderíamos dizer que toda forma de comunicação seria, em si mesma, comunitária, na medida em que apresenta posições em comum entre os envolvidos? O que o termo comunitário acrescentaria como qualificativo de comunicação? O termo não sugere uma redundância?

Paiva, que dedica sua tese de doutorado ao tema, realiza esforços significativos para diferenciar os veículos de perfil comunitário dos demais. Associando-se a Marcondes ${ }^{19}$, a autora destaca dois atributos que poderiam qualificar um processo comunicativo como comunitário. O primeiro está relacionado aos conteúdos comunicados. Segundo a autora, este tipo de comunicação surge da percepção sobre o caráter enviesado e deslocado dos conteúdos veiculados pelos canais convencionais de massa e, a partir daí, do desejo de produzir informações que tratem de problemas locais e o faça de modo mais fidedigno. Outro atributo destacado pelos autores seria a participação da comunidade na elaboração da programação a ser veiculada. Por mais que o veículo seja de propriedade particular, só poderia ser caracterizado como comunitário caso as pessoas da localidade tenham uma participação ativa na definição dos conteúdos e dos enfoques a serem adotados. Portanto, um veículo comunitário seria aquele que trata de temas relevantes à comunidade, de modo formativo (e não meramente informativo), e que conta com a participação da própria comunidade em seu funcionamento cotidiano ${ }^{20}$.

Peruzzo, uma das principais referências sobre o tema, insere alguns outros atributos ao mesmo:

Por tudo o analisado, a comunicação comunitária - que por vezes é denominada popular, alternativa ou participativa - se caracteriza por processos de comunicação baseados em princípios públicos, como não ter fins lucrativos, propiciar a participação ativa da população, ter - preferencialmente - propriedade coletiva e difundir conteúdos com a finalidade de desenvolver a educação, a cultura e ampliar a cidadania. Engloba os meios tecnológicos e outras modalidades de canais de expressão sob controle de associações comunitárias, movimentos e organizações sociais sem fins lucrativos ${ }^{21}$.

Nós, do Laboratório de Comunicação Dialógica, também definimos a comunicação comunitária, num primeiro momento, como um modo de comunicar que funciona à margem do mercado, ou seja, que não tem como objetivo principal a obtenção de lucros para alguma das partes envolvidas, mas, sim, o desenvolvimento humano de indivíduos e grupos sociais.
18. DEWEY apud WIRTH, L. Delineamentos e problemas da comunidade. In: FERNANDES, F. (org.). Comunidade e sociedade: leituras sobre problemas conceituais, metodológicos e de aplicação. São Paulo: Nacional/Edusp, 1973, p. 231.

19. MARCONDES FILHO, Ciro. Quem manipula quem - Poder e massas na indústria da cultura e da comunicação no Brasil. Petrópolis: Vozes, 1986.

20. PAIVA, op. cit.

21. PERUZZO, Cicilia. Os conceitos de comunicação popular, alternativa e comunitária revisitados. Palabra Clave. La Plata, Universidad de la Sabana, v. 11, 2008, pp. 367-379. 
22. QUIRÓS, Julieta. Cruzando la Sarmiento: una etnografia sobre piqueteros en la trama social del sur del gran Buenos Aires. Buenos Aires: Antropofagia, 2006.

23. SIGAUD, Lygia; MACEDO, Marcelo E.; ROSA, Marcelo C. Ocupações e acampamentos - Sociogênese das mobilizações por reforma agrária no Brasil. Coleção Cultura e Economia. Rio de Janeiro: Garamond, 2010.

24. PERUZZO, op. cit.

25. PAIVA, op. cit.

26. SCHENKEL, Peter. La integración Latino Americana y el desarrollo. Cuadernos de Chasqui. Quito: Ciespal, 1984.

27. BAKHTIN, Mikhail. The Dialogic Imagination: Four Essays. Austin: Michael Holquist/University of Texas Press, 1981.
No entanto, ao longo dos nossos estudos, percebemos a fragilidade dessa definição. Se, por um lado, tem o mérito de ser centrada em um dos pontos nevrálgicos da questão, por outro, reforça a dicotomia economia (lucro) $\times$ política (desenvolvimento social) na análise da mobilização social, o que a bibliografia sobre o tema já demonstrou ser equivocada ${ }^{22}$. É muito difícil separar a dimensão econômica das outras esferas nos processos de tomada de decisão. Raramente as pessoas tomam decisões pensando somente em um aspecto, mas em geral contrapõem os diversos lados envolvidos nessa decisão. Sabe-se que a motivação para mobilização social depende de um conjunto de condições sociais que muitas vezes é contingencial ${ }^{23}$.

Além disso, é difícil determinar o que é lucro e o que é remuneração pelo trabalho realizado. Nas sociedades capitalistas, a remuneração pelo trabalho não guarda relação com a contribuição social oferecida pelos resultados do mesmo. A variação salarial para exercer uma mesma função pode ser muito grande de uma organização para outra, e mesmo dentro de uma mesma organização. O fato é que as pessoas precisam sustentar as suas necessidades e desejos de alguma forma e há enormes variações de caso para caso sobre o que é necessário, o que é desejável e o que é suficiente para satisfazer esses desejos e necessidades. Portanto, o caráter voluntário das iniciativas comunitárias não pode ser definitivo como critério de conceituação.

\section{PARA SER COMUNITÁRIA A COMUNICAÇÃO PRECISA SER DIALÓGICA}

Temos a impressão que Peruzzo ${ }^{24}$ não discordaria dos argumentos de Paiva ${ }^{25}$ que, concordando com Schenkel ${ }^{26}$, afirma que o fundamental para a comunicação comunitária é o fornecimento de subsídios para promoção da participação e da dialogia no processo comunicativo. Concordamos que é o grande diferencial desse tipo de comunicação. Mas o que estaríamos chamando de dialogia? De onde vem e qual a relevância desse conceito para a comunicação comunitária?

O primeiro autor a desenvolver o conceito de dialogia foi Mikhail Bakhtin, filósofo russo que trouxe contribuições fundamentais à Linguística e às Ciências Sociais a partir das primeiras décadas do século passado. O conceito de dialogia (ou o dialogismo) é central para as teorias do autor, estando presente em diversas de suas obras, mas sendo mais detalhadamente desenvolvido no texto "The Dialogic Imagination"27.

Bakhtin parte do pressuposto que é na interação com os outros que os indivíduos se constituem enquanto seres humanos e sociais. Essa interação ocorre principalmente por meio da linguagem e o autor chama de diálogo a troca de influências ocorrida por meio das interações verbais. Segundo ele, qualquer enunciado pressupõe um movimento de reflexão e resposta por parte de um interlocutor que, ao fazer a réplica, suscitará uma tréplica e assim sucessivamente. Bakhtin vai nos mostrar que as relações sociais e, portanto, a história, se 
formam e transformam permanentemente por meio do diálogo entre pessoas com trajetórias individuais específicas, que as vinculam a ideologias específicas e que ocorrem em contextos sociais também específicos. Cabe ao linguista e ao cientista social saber ler e compreender esses movimentos. Como exemplo de sua proposta teórico metodológica, o autor utiliza a história e a obra de Rabelais para compreender o Carnaval e formular sua teoria sobre a relação entre a ocupação dos espaços públicos e a cultura popular. Em última instância, poderíamos dizer que o autor nos mostra como sua filosofia da comunicação ao mesmo tempo expressa e é reflexo do materialismo dialético proposto por $\mathrm{Marx}^{28}$.

Podemos dizer que essas ideias constituem as bases para a concepção de Dewey $^{29}$ sobre a comunicação como o processo que expõe o que há de comum e o que há de diferente entre as pessoas. E que é nesse processo que as pessoas se constituem como seres sociais, mais ou menos democráticos, de acordo com a abertura a que se dispõem nessas trocas de influências verbais. A capacidade de ouvir o outro - que, de fato, traz consigo semelhanças, mas, quase sempre, diferenças -, de divergir respeitosamente, de concordar, de cooperar, colaborar, é o que confere ao homem as habilidades para o exercício político, no sentido de se fazer um ser responsável pelos seus atos e capaz de compreender os atos dos seus próximos na pólis.

Do ponto de vista da Teoria da Comunicação, poderíamos dizer que a comunicação dialógica contrapõe-se ao modelo cibernético, que prevê o fluxo de informações a partir de um emissor, que transmite mensagens por um canal, com a interferência de ruídos, para um receptor, que pode ou não oferecer um retorno. Nesse modelo está implícita a pressuposição de que alguém tem algo para informar a outrem, que alguém tem conhecimentos a serem transmitidos a outros que não o possuem e, portanto, que há uma diferenciação hierárquica entre os envolvidos. O que nos parece sugerir, acima de tudo, essa concepção de comunicação é a ênfase ao caráter de troca que envolve o processo comunicativo, é a acentuação do caráter horizontal desse processo. Em última instância, é a percepção do fluxo informacional a partir de uma perspectiva democrática. Toda a teoria de Paulo Freire foi construída a partir dessa perspectiva. Segundo o autor:

[...] o diálogo é uma exigência existencial. E, se ele é o encontro em que se solidarizam o refletir e o agir de seus sujeitos endereçados ao mundo a ser transformado e humanizado, não pode reduzir-se ao ato de depositar ideias de um sujeito no outro [...] porque é encontro de homens que pronunciam o mundo, não deve ser doação do pronunciar de uns a outros. É um ato de criação. Daí que não pode ser um manhoso instrumento de que lance mão um sujeito para a conquista do outro. A conquista implícita no diálogo é a conquista do mundo pelos sujeitos dialógicos, não a de um pelo outro. Conquista do mundo para a libertação dos homens ${ }^{30}$.

A partir desse percurso teórico, concluímos que o termo que melhor qualifica e expressa o tipo de comunicação que estamos estudando e promovendo é "dialógica", embora ao longo da história recente este tenha sido chamado com
28. BAKHTIN, Mikhail. Marxismo e filosofia da linguagem. São Paulo: Hucitec, 2009.

29. DEWEY apud WIRTH, L., op. cit.

30. FREIRE, Paulo. Pedagogia do oprimido. 17. ed. Rio de Janeiro: Paz e Terra, 1987, p. 79. 
alguns outros nomes, tais como "comunitária”, "popular", "crítica”, "alternativa”, muito bem traduzidos por Peruzzo em um artigo que procura examinar as peculiaridades de cada um desses termos ${ }^{31}$. Entendemos que todos trazem em si alguma imprecisão ou desgaste, seja pelo debate teórico ou pelo próprio uso pelo senso comum. Por isso, o laboratório que criamos na Uerj para estudar, pesquisar e desenvolver atividades de extensão sobre esse tema tem como nome "Laboratório de Comunicação Dialógica".

\section{REFERÊNCIAS}

ADORNO, Theodor; HORKHEIMER, Max. Aindústria cultural-O esclarecimento como mistificação das massas. In: Dialética do esclarecimento. Rio de Janeiro: Zahar, 2006.

BAKHTIN, Mikhail. Marxismo e filosofia da linguagem. São Paulo: Hucitec, 2009.

. The Dialogic Imagination: Four Essays. Austin: Michael Holquist/ University of Texas Press, 1981.

BAUMAN, Zygmunt. Comunidade - A busca por segurança no mundo atual. Rio de Janeiro: Jorge Zahar Editor, 2003.

BOURDIEU, Pierre. O poder simbólico. Rio de Janeiro: Bertrand Brasil, 1989.

CANDIDO, Antonio. 1975. O caipira e sua cultura. In: FERNANDES, Florestan (org.). Comunidade e sociedade no Brasil. São Paulo: Nacional, 1975.

COSTA, R. Por um novo conceito de comunidade: redes sociais, comunidades pessoais e inteligência coletiva. Interface - Comunicação, Saúde e Educação. São Paulo, Unesp, v. 9, n.17, mar./ago. 2005.

DELEUZE, Gilles ; GUATTARI, Félix. Mil platôs - Capitalismo e esquizofrenia. Coleção Trans. Rio de Janeiro: Editora 34, 1995.

FERNANDES, Florestan (org.). Comunidade e sociedade: leituras sobre problemas conceituais, metodológicos e de aplicação. São Paulo: Nacional, 1973.

. Comunidade e sociedade no Brasil. São Paulo: Nacional, 1975.

FREIRE, Paulo. Pedagogia do oprimido. 17. ed. Rio de Janeiro: Paz e Terra, 1987. LÉVY, Pierre. Cibercultura. Rio de Janeiro: Editora 34, 1999.

MACEDO, Marcelo Ernandez. Zé Pureza - Etnografia de um acampamento no norte fluminense. Tese de doutorado. Rio de Janeiro: PPCIS/Uerj, 2003.

Entre a violência e a espontaneidade: reflexões sobre os processos de mobilização para ocupações de terra no Rio de Janeiro. Mana - Estudos de antropologia social. Rio de Janeiro, Museu Nacional/UFRJ, n. 11, n. 2, 2005. 
MARCONDES FILHO, Ciro. Quem manipula quem - Poder e massas na indústria da cultura e da comunicação no Brasil. Petrópolis: Vozes, 1986.

MARX, Karl. O capital - Crítica da economia política. 19. ed. Rio de Janeiro: Civilização Brasileira, 2002.

PAIVA, RAQUEL. O espírito comum - Comunidade, mídia e globalismo. Rio de Janeiro: Mauad, 2003.

PERUZZO, Cicilia. Os conceitos de comunicação popular, alternativa e comunitária revisitados. Palabra Clave. La Plata, Universidad de la Sabana, v. 11, 2008.

QUEIROZ, Maria Isaura Pereira. 1975. O povoado de Santa Brígida. In: FERNANDES, Florestan (org.). Comunidade e sociedade no Brasil. São Paulo: Nacional, 1975.

QUIRÓS, Julieta. Cruzando la Sarmiento: una etnografia sobre piqueteros en la trama social del sur del gran Buenos Aires. Buenos Aires: Antropofagia, 2006.

SENNETT, Richard. A corrosão do caráter - Consequências pessoais do trabalho no novo capitalismo. Rio de Janeiro: Record, 1999.

SCHENKEL, Peter. La integración Latino Americana y el desarrollo. Cuadernos de Chasqui. Quito: Ciespal, 1984.

SIGAUD, Lygia. A forma acampamento: notas a partir da versão pernambucana. Novos Estudos. Cebrap, São Paulo, n. 58, nov. 2000.

SIGAUD, Lygia; MACEDO, Marcelo E.; ROSA, Marcelo C. Ocupações e acampamentos - Sociogênese das mobilizações por reforma agrária no Brasil. Coleção Cultura e Economia. Rio de Janeiro: Garamond, 2010.

WAGLEY, C.; GALVÃO, E. 1975. Caboclização das comunidades Tenetehara. In: FERNANDES, Florestan (org.). Comunidade e sociedade no Brasil. São Paulo: Nacional, 1975.

WEBER, Max. Economia e sociedade. Brasília: Editora UNB, 1991.

WIRTH, L. Delineamentos e problemas da comunidade. In: FERNANDES, F. (org.). Comunidade e sociedade: leituras sobre problemas conceituais, metodológicos e de aplicação. São Paulo: Nacional/Edusp, 1973. 